\title{
Oral rehydration therapy for treatment of rotavirus diarrhoea in a rural treatment centre in Bangladesh
}

\author{
P R TAYLOR, M H MERSON, R E BLACK, A S M MIZANUR RAHMAN, M D YUNUS, \\ A R M A ALIM, AND R H YOLKEN
}

Los Angeles County Department of Health Services, Field Services Division, Bureau of Epidemiology, Center for Disease Control, Public Health Service, Atlanta, Georgia, USA, International Centre for Diarrhoeal Diseases Research, Dacca, Bangladesh, and Laboratory of Infectious Diseases, National Institute of Allergy and Infectious Diseases, Bethesda, Maryland, USA

SUMMARY In November 1977, an enzyme-linked immunosorbent assay for detecting rotavirus antigen was introduced in the laboratory of a rural treatment centre in Bangladesh. During the next 40 days rotavirus without other pathogens was found in the stools of $216(45 \%)$ of 480 children under age 5 years who visited the centre with a gastrointestinal illness. $188(87 \%)$ of these children were treated with oral rehydration alone, using the solution currently recommended by the World Health Organisation, while $28(13 \%)$ also required some intravenous rehydration; there were no deaths. Oral rehydration treatment was judged successful in $205(95 \%)$ of the rotavirus patients and was not associated with any serious side effects. Oral rehydration treatment, with this solution, has been used extensively and successfully in the treatment of enterotoxin-mediated diarrhoea and can also safely be used for treating rotavirus diarrhoea in infants and young children.

Rotaviruses have been identified as a cause of gastroenteritis in infancy and early childhood in many parts of the world including some developing countries. ${ }^{1-4}$ Because rotavirus disrupts the structure of the small intestine and generally causes diarrhoea in infants and young children, there is concern about whether the oral glucose electrolyte solution recommended by the World Health Organisation $\left(\right.$ WHO) ${ }^{5}$ (which contains $90 \mathrm{mmol} / 1$ sodium and $111 \mathrm{mmol} / 1$ glucose) can be used on a large scale for standard treatment of rotavirus diarrhoea. ${ }^{6-7}$ An enzyme-linked immunosorbent assay (ELISA) for

Chronic Diseases Division, Bureau of Epidemiology, Center
for Disease Control
P R TAYLOR, epidemiologist
Center for Vaccine Development, Division of Infectious
Diseases, University of Maryland School of Medicine,
Baltimore,
R E BLACK, chief, epidemiology
Diarrhoeal Diseases Control Programme, World Health
Organisation, Geneva
M H MERSON, medical officer
International Centre for Diarrhoeal Diseases Research, Dacca,
Bangladesh
A S M MIZANUR RAHMAN, physician
M D YUNUS, physician
A R M A ALIM, laboratory assistant
Department of Pediatrics, Johns Hopkins University, Balti-
more, Maryland
R H YOLKEN, assistant professor

rotavirus detection was recently developed; it has been described as being rapid, accurate, sensitive, and suitable for field work. ${ }^{8-9}$ In November 1977 we introduced ELISA in the laboratory of our rural treatment centre for use when routinely examining stools from patients with gastroenteritis. We describe here the outcome of rehydration treatment during the subsequent 40-day period, using the solution recommended by WHO, on 216 children aged under 5 years.

\section{Materials and methods}

Matlab Hospital is the rural treatment centre of the International Centre for Diarrhoeal Diseases Research, Bangladesh (formerly the Cholera Research Laboratory). It is about 40 miles south-east of Dacca and is the primary treatment centre for gastrointestinal illness, serving a population of about 269000 . Medical care at the centre is given by paramedical staff under supervision of a physician. Before treatment is started, a brief history is obtained and the patient is weighed. All patients are treated on cholera cots to determine the accurate stool volume. At the time of the evaluation patients who did not appear clinically dehydrated on presentation, or who were slightly dehydrated (judged clinically to have lost up to $5 \%$ body weight), 
received oral glucose electrolyte solution prepared at the centre following WHO guidelines. ${ }^{5}$ Mothers were instructed to give oral fluid to these children ad lib. in frequent small feeds and were encouraged to continue breast feeding. Those patients presenting with moderate $(5-10 \%$ body weight loss) or severe ( $>10 \%$ body weight loss) dehydration were initially given intravenous rehydration fluid according to a standard regimen to replace initial losses, and then given the oral rehydration solution ad lib. to replace continuing losses. Plain water was offered later in the course of treatment to any child who appeared thirsty but showed no evidence of dehydration, or if requested by his mother.

In the course of receiving oral rehydration treatment, any patient in either group who was judged by the staff to be unable to consume enough oral fluid to match fluid loss (diarrhoea and vomitus) because of persisting vomiting or high purging rates, or both, was considered an oral treatment failure and was then given fluid intravenously. Patients were sent home when they were fully rehydrated and their diarrhoea minimal (generally less than $5-10 \mathrm{ml} / \mathrm{kg}$ and usually no diarrhoea in the previous 8-hour period). Before discharge each patient was weighed.

From 17 November 1977 two rectal swabs were obtained before treatment from any patient living in our vaccine trial surveillance area. The first rectal swab was used to test for bacterial pathogens including vibrio, salmonellae, and shigellae using standard procedure ${ }^{10}$ and for enterotoxigenic Escherichia coli as previously described. ${ }^{11}$ The second rectal swab was placed in phosphate buffered saline pH 7.4 and tested for rotavirus antigen by the ELISA of Yolken et al. ${ }^{8}$ using the 2-antibody technique. ${ }^{9}$ Blocking tests were performed in specimens from 120 cases and were positive in all. Any patient in whom rotavirus was identified in his stools was defined as a case of rotavirus.

\section{Results}

480 patients under age 5 years who visited the treatment centre with gastroenteritis between 17 November and 26 December 1977 were studied. Rotavirus was identified in $232(48 \%)$ of them. In $16(3 \%)$ of the 232 cases a bacterial pathogen was also isolated; these cases were excluded from this analysis.

The mean age of patients with rotavirus was 11.8 months; $99 \%$ of the children were younger than 2 years and $93 \%$ were between 6 and 23 months. The highest frequency of detection was in the 12- to 17 month age group where 97 (64\%) of 152 children had rotavirus infection. The male to female ratio was $1 \cdot 2: 1$.
Clinical features of the rotavirus cases are shown in Table 1. Diarrhoea and vomiting were almost universal. The diarrhoea was described as watery in most cases; bloody diarrhoea was reported by only one. $62(29 \%)$ patients reported a history of fever, and fever $\left(>37 \cdot 8^{\circ} \mathrm{C}\right.$ rectally) was documented in 45 $(22 \%)$ cases. On presentation to the centre most of the rotavirus cases had slight dehydration or none; only $9 \%$ had moderate or severe dehydration. Patients were treated a mean of 16 hours and purged on the average $131 \mathrm{ml} / \mathrm{kg}$ (excluding 36 patients who did not purge after visiting the centre). The maximum amount of total stool purged was $1990 \mathrm{ml}$. Average amount of total fluid intake in all patients was $130 \mathrm{ml} / \mathrm{kg}$. Plain water was consumed by $5 \%$ of patients. Mean weight gain after rehydration was $100 \mathrm{~g}$, or $1.4 \%$ body weight.

The outcome of treatment of these patients is shown in Table 2 . Nine $(5 \%)$ of the 197 cases with slight dehydration or none and treated initially with oral fluid, and $2(11 \%)$ of the 19 moderate or severely dehydrated cases who were treated initially with intravenous fluid were oral fluid failures; the overall oral treatment failure rate was $5 \%$. Oral treatment successes decreased with increasing degree of dehydration and, as expected, were

Table 1 Clinical characteristics of 216 patients with rotavirus

\begin{tabular}{lrl}
\hline Symptoms and signs & No. & Frequency $(\%)$ \\
\hline Diarrhoea & 214 & 99 \\
Watery & 202 & 94 \\
Mucous & 52 & 24 \\
Bloody & 1 & $<1$ \\
Vomiting & 207 & 96 \\
Fever (reported) & 62 & 29 \\
& & \\
Dehydration & 121 & 56 \\
None & 76 & 35 \\
Slight & 17 & 8 \\
Moderate & 2 & 1 \\
Severe & 45 & 22 \\
Fever $\left(>37 \cdot 8^{\circ} \mathrm{C}\right.$ rectal) &
\end{tabular}

Mean duration diarrhoea before visit, $37 \pm 2 \cdot 1$ hours.*

Mean duration of treatment, $16 \pm 1 \cdot 8$ hours.

Mean purging rate, $131 \pm 21 \mathrm{ml} / \mathrm{kg}$ discharge weight.

Mean total fluid intake, $130 \pm 17 \mathrm{ml} / \mathrm{kg}$ discharge weight.

Mean weight gain after rehydration, $100 \pm 21 \mathrm{~g}(1.4 \pm 0.4 \%$ body weight).

*All mean values recorded with \pm 1 SEM.

Table 2 Outcome of oral treatment of 216 patients with rotavirus

\begin{tabular}{lll}
\hline Initial treatment & \multicolumn{2}{l}{ Oral treatment } \\
\cline { 2 - 3 } & Success & Failure* \\
\hline Oral $(\mathrm{n}=197)$ & $188(95)$ & $9(5)$ \\
Intravenous $(\mathrm{n}=19)$ & $17(89)$ & $2(11)$ \\
Total $(\mathrm{n}=206)$ & $205(95)$ & $11(5)$ \\
\hline
\end{tabular}

* Requiring unscheduled treatment intravenously. Percentages are given in parentheses. 
Table 3 Frequency of oral rehydration successes by dehydration status in rotavirus cases

\begin{tabular}{lccc}
\hline Dehydration & No. cases & \multicolumn{2}{c}{ Successes with oral treatment } \\
\cline { 3 - 4 } & & No. & $\%$ \\
\hline None & 121 & 119 & 98 \\
Slight & 76 & 69 & 90 \\
Moderate/severe & 19 & 17 & 90
\end{tabular}

Success rate higher in group with no dehydration than in those with slight, moderate, and severe dehydration $\left(\chi^{2}=6 \cdot 73, \mathrm{P}<0.01\right)$.

significantly more common in the group with no dehydration at the time of hospital visit (Table 3). Vomiting occurred during the course of oral treatment in $9(82 \%)$ failures and $65(32 \%)$ oral treatment successes $(P<0 \cdot 001)$. There were no deaths and no serious side effects associated with the rehydration.

We found that the ELISA was easy to use and could be read with the naked eye. Almost all reactions could be read as clearly positive or negative within 10-15 minutes after adding the substrate to the plate. The average room temperature in our field laboratory was $35^{\circ} \mathrm{C}$.

\section{Discussion}

The use of the ELISA in our field laboratory has shown us the great importance of rotavirus as an aetiological agent in infants and young children in our population and has helped to evaluate the effectiveness of oral rehydration in the treatment of rotavirus diarrhoea. Our finding that during this 40-day period $48 \%$ of cases in children below age 5, most of whom were 6-24 months, were associated with this pathogen is similar to results reported from other developing ${ }^{3}$ and developed countries. ${ }^{12-13} \mathrm{We}$ are currently studying the seasonal pattern of the disease to see what proportion of persons with rotavirus infection in our field area visit our centre for treatment. The almost universal symptoms were diarrhoea with vomiting, sometimes with fever, as has been described by others. ${ }^{2}$ 14-16 However, unlike the impression given in other studies, we found that the disease has a broad clinical spectrum; $56 \%$ of our patients had no evidence of dehydration on presentation and $17 \%$ did not purge while under treatment.

Oral rehydration treatment was successful for treating rotavirus diarrhoea in $95 \%$ of children. Intravenous rehydration was required initially in only $9 \%$ of cases and eventually in only $13 \%$. These numbers are a little higher than those reported previously in other carefully controlled studies of rotavirus diarrhoea in our urban hospital ${ }^{14}$ and at another hospital ${ }^{17}$ but this can be attributed to the more difficult circumstances in our rural centre where our paramedical staff are faced with treating a much greater number of patients under less closely supervised conditions. Those who failed on oral treatment in our centre generally had some dehydration on initial presentation or had repeated attacks of vomiting. Vomiting however was not a major problem; $88 \%$ of children who vomited in the hospital were successfully treated orally.

We found that in our treatment centre, where infants and young children are generally breast fed, the oral rehydration fluid, which has the electrolyte composition currently recommended by WHO and contains $90 \mathrm{mmol} / \mathrm{l}$ sodium and $111 \mathrm{mmol} / \mathrm{l}$ glucose, can be used without serious side effects for treatment of rotavirus diarrhoea. Since this formulation has now been demonstrated to be safe and efficacious in adults and in infants and young children with enterotoxin-mediated diarrhoea ${ }^{17-18}$ (enterotoxigenic $E$. coli diarrhoea, and cholera), which together with rotavirus are responsible for about $75-80 \%$ cases of diarrhoea seen at our treatment centre, ${ }^{19}$ we feel that its use can be justified for treatment of all our cases of acute diarrhoea.

\section{References}

1 Maiya P P, Pereira S M, Mathan M, Bhat P, Albert M J, Baker S J. Aetiology of acute gastroenteritis in infancy and early childhood in southern India. Arch Dis Child 1977; 52: 482-5.

2 Ryder R W, Sack D A, Kapikian A Z, et al. Enterotoxigenic Escherichia coli and reovirus-like agent in rural Bangladesh. Lancet 1976; i: 659-62.

8 Viera de Torres B, Mazzali de Ilja R, Esparza J. Epidemiologic aspects of rotavirus infection in hospitalized Venezuelan children with gastroenteritis. Am J Trop Med Hyg 1978; 27 : 567-72.

4 Wyatt R G, Yolken R H, Urrutia J J, et al. Diarrhea associated with rotavirus in rural Guatemala: a longitudinal study of 24 infants and young children. $A m ~ J$ Trop Med Hyg 1979; 28: 325-8.

5 World Health Organisation. Treatment and prevention of dehydration in diarrheal diseases. A guide for use at the primary level. Geneva: WHO, 1976.

- Davidson G P, Gall D G, Petric M, Butle: D G, Hamilton $J$ R. Human rotavirus enteritis induced in conventional piglets, J Clin Invest 1977; 60 : 1402-9.

7 Nichols B L, Soriano A A. A critique of oral therapy of dehydration due to diarrheal syndromes. Am J Clin Nutr 1977; 30: 1457-72.

8 Yolken R H, Kim H W, Chen T, et al. Enzyme-linked immunoassay (ELISA) for detection of human reoviruslike agent of infantile gastroenteritis. Lancet 1977; ii: 263-7.

- Yolken R H, Wyatt R G, Kapikian A Z. Letter: ELISA for rotavirus. Lancet 1977; ii : 819.

10 Edwards P R, Ewing W H. Identification of enterobacteriaceae. 3rd ed. Minneapolis: Burgess, 1972.

11 Merson M H, Sack R B, Golam Kibria A K M, AlMahmood A, Adamed Q S, Huq I. Use of colony pools for diagnosis of enterotoxigenic Escherichia coli diarrhea. $J$ Clin Microbiol 1979; 9: 493-7. 
12 Kapikian A Z, Kim W H, Wyatt R G, et al. Human rotavirus agent as the major pathogen associated with 'winter' gastroenteritis in hospitalized infants and young children. N EnglJ Med 1976; 294 : 965-72.

13 Middleton P J, Szymanski M T, Petric M. Viruses associated with acute gastroenteritis in young children. Am J Dis Child 1977; 131: 733-7.

14 Sack D A, Chowdhury A M A K, Eusof A, et al. Dehydration in rotavirus diarrhoea: a double blind comparison of sucrose with glucose electrolyte solution. Lancet 1978; ii : 280-3.

15 Shepherd R W, Truslow S, Walker-Smith J A, et al. Infantile gastroenteritis: a clinical study of reovirus-like agent infection. Lancet 1975 ; ii : $1082-4$.

16 Tallet S, MacKenzie C, Middleton P, Kerner B, Hamilton R. Clinical, laboratory, and epidemiologic features of a viral gastroenteritis in infants and children. Pediatrics 1977; 60: 217-22.

17 Nalin D R, Levine M M, Mata L, et al. Comparison of sucrose with glucose in oral therapy of infantile diarrhoea. Lancet 1978; ii : 277-9.

18 Mahalanabis D, Choudhuri A G, Bagchi N G, Bhattacharya A K, Simpson T W. Oral fluid therapy of cholera among Bangladesh refugees. Johns Hopkins Med J 1973; 132:197-205.

19 Merson M H, Black R E, Kahn M U, Huq I. Epidemiology of cholera and enterotoxigenic Escherichia coli diarrhoea. In: Ouchterlony $\mathbf{O}$, Holmgren $\mathrm{J}$, eds. Cholera and related diarrhoeas-molecular aspects of a global health problem. Nobel Symposium 43, 1978. Basel: Karger,1980: in press.

Correspondence to Dr $\mathbf{P} \mathbf{R}$ Taylor, Bureau of Epidemiology, Chronic Diseases Division, Center for Disease Control, Atlanta, Georgia 30333, USA.

Received 23 May 1979 